\title{
Canal e forame retromolar: prevalência e características anatômicas em imagens de Tomografia Computadorizada de Feixe Cônico
}

Dissertação apresentada a Faculdade de Odontologia de Bauru da Universidade de São Paulo para obtenção do título de Mestre em Ciências no Programa de Ciências Odontológicas Aplicadas, na área de concentração em Estomatologia e Radiologia.

Orientadora Prof. a Dra. Cássia Maria Fischer Rubira

\section{BAURU}




\section{RESUMO}

O forame retromolar (FRM) e o canal retromolar (CRM) estão situados na fossa retromolar e são delimitados pela borda anterior do ramo e a crista temporal da mandíbula. $O$ objetivo desta pesquisa foi determinar a prevalência do canal retromolar, analisando o tipo e o trajeto do canal, e a correlação com a presença do terceiro molar, com a idade e o sexo do paciente. A amostra foi composta por 200 exames de Tomografia Computadorizada de Feixe Cônico (TCFC). Foi mensurado o diâmetro e a distância que o canal se encontrava do último dente presente. Então, seguiu-se a seguinte ordem de avaliação da imagem: dados gerais (sexo e idade), presença ou ausência do CRM, tipo e trajeto quando o CRM estava presente, mensurações dos diâmetros inicial e final, localização vestibulolingual. Como resultados, a prevalência do CRM foi de $24,5 \%$ da amostra ( $n=49 / 200$ ). O trajeto oblíquo foi o mais comum na amostra (33,3\% lado direito e 50\% lado esquerdo). O destino final mais comum do CRM foi em direção mesial ( $86,2 \%$ lado direito e $82,1 \%$ lado esquerdo). Nas mensurações dos diâmetros, no diâmetro inicial, do lado direito, a média foi de $1,5 \mathrm{~mm}$ e do lado esquerdo a média foi de $1,4 \mathrm{~mm}$. No diâmetro final, do lado direito a média foi de 1,3 $\mathrm{mm}$ e do lado esquerdo a média foi de $1,3 \mathrm{~mm}$. Quanto a localização do CRM na mandíbula em relação a vestibular e a lingual, do lado direito $50 \%$ estavam vestibularizados e $50 \%$ estavam lingualizados. Do lado esquerdo $70 \%$ estavam vestibularizados e $30 \%$ lingualizados. Não se encontrou correlação entre a presença do CRM com o sexo (presença do CRM em 25,4\% das mulheres e $23,3 \%$ dos homens) e terceiro molar (lado direito presença do CRM em $56,5 \%$ e do lado esquerdo em $60,5 \%$ ). Para verificação de associação, realizou-se teste Qui-Quadrado. Em conclusão o trabalho mostrou a prevalência do CRM como de $24,5 \%$ na amostra, demostrando, portanto, que essa variação anatômica não é uma condição rara, sendo necessário considera-la em procedimentos que envolvam a área retromolar.

Palavras chaves: Variação Anatômica. Tomografia Computadorizada de Feixe Cônico. Mandíbula. Anatomia. Terceiro Molar. 